\title{
Long term closure planning for an evolving mine site - a case study of Newmont Boddington Gold Mine in Western Australia
}

\author{
K. De Sousa Newmont Asia Pacific, Australia \\ N. Amoah Newmont Asia Pacific, Australia
}

\begin{abstract}
Newmont Boddington Gold (NBG) mine is located $12 \mathrm{~km}$ northwest of the town of Boddington and about $120 \mathrm{~km}$ southeast of Perth in Western Australia (WA). Open pit mining of an oxide gold resource commenced at the operations in 1987. In 2008, NBG undertook an expansion program to increase future gold production to one million ounces per annum, potentially becoming the largest gold mine in Australia.

Critical to the life cycle of such a large mining operation is the need to ensure that mine closure is well planned in advance and consistently managed throughout operation to minimise future liabilities. For example, the large quantities of waste (waste rock estimated to be over one billion tonnes over the life of the mine), vast open pits and areas for tailings storage and site operational facilities, geographically and ecologically sensitive location and socio-economic issues will all become significant legacy factors during mine closure and post closure stages.

To mitigate closure liabilities, Newmont's internal guidelines have strict requirements for the development and review of closure plans at all stages of mine life with annual analyses of closure liability costs. This is to ensure consistency with life of mine (LOM) plans, changes in operations, stakeholder expectations, regulatory requirements etc. However, planning and managing closure for such a large, complex and evolving mine poses challenges. The recent changes to the mine closure planning guidelines in WA, rapidly changing community expectations and Newmont's growth plans add to the complexities.

The paper discusses the on-going activities for an integrated life of mine and closure planning approach that will ensure that operational decisions are consistent with closure requirements and environmentally sustainable operation of the mine to minimise long-term liabilities. How recent closure planning activities have assisted in optimising the design and operation of the expanded mine, especially in the areas of waste rock landform location, size and capping will be presented. Closure planning activities such as knowledge gap analysis, risk analysis-based approach to prioritising activities and development of completion criteria as well as current studies and investigations to address knowledge gaps in waste rock geochemistry, post closure facilities management, closure water management, rehabilitation trials, tailings decommissioning plans, closure cost estimating and financial provisions for closure liabilities are discussed.
\end{abstract}

\section{Introduction}

In recent years, community awareness of the need to protect the environment and consequent demand for social responsibility have put more pressure on governments to ensure that adverse impacts of mining operations on local communities are minimised at all times, including closure and post closure stages. Furthermore, the demand for rapidly depleting mineral resources has led to many companies (especially in the gold sector) needing to explore areas of high cultural, ecological and geographical sensitivity. Others have had to look into very low grade ore bodies, resulting in generation of significant volumes of waste rock and tailings that present challenging environmental obligations at mine closure.

Governments have responded to these pressures by applying more stringent regulatory conditions on mine closure planning. In many countries, including Australia, comprehensive mine closure plans that detail the 
rehabilitation management strategies during operation, closure and post closure stages are required for mining approval.

Developing a closure plan for a constantly evolving mining operation in a framework of changing regulatory and community expectations is a major challenge faced by mining companies including NBG Mine. In the case of NBG Mine, the size of the operation, its location in a geographically and ecologically sensitive area and Newmont's regularly changing growth plan for the site add to the complexity of the closure planning process. For example, NBG is currently undergoing a re-permitting process to increase mine life from 2035 to approximately 2060, which will require an increase in the disturbance footprint to store additional waste.

To mitigate closure liabilities, Newmont's internal guidelines have strict requirements for the development of closure plans at all stages of mine life with an annual review of closure liability costs and periodic review of plans to ensure they are consistent with LOM plans, changes in operations, stakeholder expectations and regulatory requirements. This paper presents an overview of the complexities and challenges associated with closure planning for a large complicated operation like NBG. Adopting an integrated approach involving multidisciplinary areas of knowledge from various departments of the mining operation and specialist consultants to plan, develop and review closure plans is critical for success.

\section{Newmont Boddington Gold project overview}

NBG Mine is located about $120 \mathrm{~km}$ southeast of Perth and $12 \mathrm{~km}$ northwest of the town of Boddington in the south west of Western Australia (Figure 1). Gold mineralisation is hosted in the Saddleback Greenstone Belt of Archean age and is exploited in two discrete zones, Wandoo North and Wandoo South. The former is characterised by porphyritic diorites and occasional fragmental volcanics. The latter comprises a series of diorite stocks emplaced in a sequence of porphyritic volcanics ranging in composition from andesite to dacite. Gold occurs in association with minor chalcopyrite, pyrrhotite and pyrite. Wandoo North and South display several distinctions with respect to alteration. Wandoo North displays relatively intense chlorite alteration, plus minor epidote and calcite while Wandoo south is virtually devoid of calcite, with actinolite and albite common.

The mine first commenced operations in 1987 and operated continually until it was placed under care and maintenance in December 2001 after exhaustion of the oxide ore deposit. In 2008, NBG undertook an expansion program to increase future gold production to one million ounces per annum. Approval was received to increase the disturbance footprint of the mine site to 3,650 ha and produce $820 \mathrm{Mt}$ of waste rock and $600 \mathrm{Mt}$ of tailings.

The NBG mining lease falls within the Darling Botanical District of the Southwestern Botanical province, which is largely characterised by open forests of Eucalyptus marginata (Jarrah), a significant commercial timber. Other dominant species include Corymbia calophylla (Marri) and Eucalyptus wandoo (Wandoo). The site includes vegetation which is considered to represent potential foraging and breeding habitat for three conservation significant species of black cockatoo, Calyptorhyncus latirostris (Carnaby's Black Cockatoo), Calyptorhyncus banksia naso (Forest Red-tailed Black Cockatoo) and Calyptorhyncus baudinii (Baudin's Black Cockatoo). Other threatened species which may occur in the vicinity of the mine are the Bettongia penicillata ogilbyi (Woylie), Phascogale calura (Red-tailed Phascogale) and Dasyurus geoffroii (Chuditch).

A number of small ephemeral creeks dissect the area, but the main river catchment is the Thirty-Four Mile Brook, which is in turn a tributary of the Hotham River. Surface water flow in Thirty-Four Mile Brook has been interrupted by the construction of diversions and dams along its length in the mining area.

The interaction of the underlying geology and the extent of weathering result in two main aquifers in the area being (i) a shallow groundwater system which is susceptible to seasonal variations in precipitation and recharge but is not responsive to mining activities; and (ii) a deeper weathered and fractured bedrock groundwater system which displays relatively little response to seasonal variation in precipitation and recharge but is responsive to mine dewatering activities. 
Primary land uses in the region include production forestry, agriculture, mining, water supply catchment, nature conservation and recreation. It is expected that all of the existing land uses can be managed in a compatible manner at the mine post closure except agriculture due to risks associated with destabilising vegetated landforms by livestock grazing.

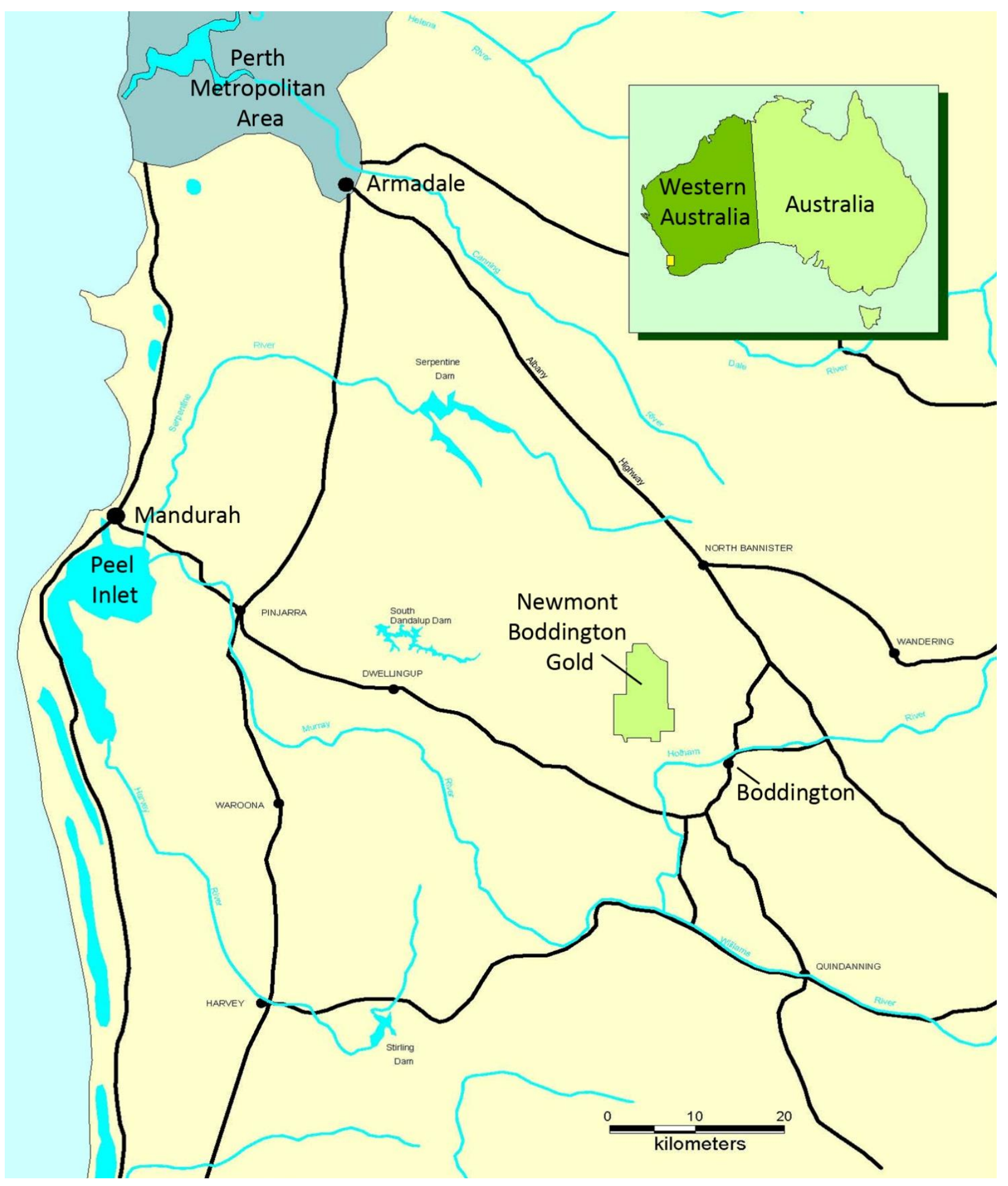

Figure 1 Location of Newmont Boddington Gold Mine 


\section{$3 \quad$ Closure planning process}

Closure planning at Newmont is carried out by a dedicated closure team based in the Asia Pacific regional head office in Perth. The regional closure team is responsible for closure planning and rehabilitation for Newmont's seven operating and legacy (closed) mines across Australia and New Zealand. The closure team focuses solely on closure planning and managing rehabilitation activities to ensure that mine closure is planned well in advance and consistently managed throughout operation of the site. Each mine site is allocated a Senior Closure Planner who coordinates all activities and manages rehabilitation works to ensure that closure planning is not overshadowed by the urgency of operational activities. The Closure Planner coordinates relevant closure activities including preparation of closure plans, development of progressive rehabilitation works plans, studies and investigations, annual review of the closure provision and risk assessment, providing support for site based personnel and ensuring compliance with regulatory conditions and Newmont's strict internal guidelines/standards.

Due to the multidisciplinary nature of the closure planning process, Newmont's closure team has adopted an integrated approach involving a cross-functional team from various departments of the mine operations and a number of discipline expert consultants that meet regularly to discuss progress on closure related investigations and key findings.

The current closure plan for NBG was developed as part of the 2006 expansion program for the site and incorporated the requirements of the Western Australian government and Newmont guidelines at the time. This closure plan has formed the basis for all closure planning activities for the current operations; however, recent changes require this plan to be updated to contemporary level, specifically to:

- Meet the requirements and structure of the new Western Australian Guidelines for Preparing Mine Closure Plans (DMP and EPA, 2011).

- Take into account the increased disturbance and accompanying closure risks and costs associated with expanding the operations.

- Ensure that all the closure-related historical commitments made in various public/regulatory documents at different stages of the mine development are fully accounted for in the long term planning process.

- To incorporate the findings of recent closure related investigations.

At NBG, several physical features of the site add to the socio-economic factors to pose significant immediate and long term challenges for closure planning. These include very large waste rock storage landforms (some of which have the potential to generate acid and/or metalliferous drainage), open pits, tailings storage facilities (TSFs) (currently over $1,500 \mathrm{Ha}$ with potential to double in size during the mines operational life), site facilities such as process areas and a 2,000 personnel accommodation village (Figure 2).

The need for adequate closure planning and regular reviews to minimise closure liability is very important to Newmont management. In order to bring the current closure plan to contemporary level, a program of activities has been undertaken over the past two years involving gap analysis, technical/scientific studies, investigations, engineering design reviews and benchmarking, in addition to Newmont's standard processes such as annual closure risk and cost reviews. The following sections discuss some of these activities.

\subsection{Gap analysis}

The existing closure plan for NBG was prepared and submitted to regulatory authorities prior to publication of the Guidelines for Preparing Mine Closure Plans (DMP and EPA, 2011). Therefore, as expected, the current document does not meet all the requirements of the new Guidelines.

A gap analysis was undertaken on the existing closure plan to identify variations from the requirements of the Guidelines as well as bridging the current closure planning knowledge gaps associated with expansion 
of the operations. From the gap analysis, a work plan was developed and a risk-based approach used to prioritise the identified gaps. A checklist of the requirements of the Guidelines was also developed to ensure all required information is included in the closure plan.

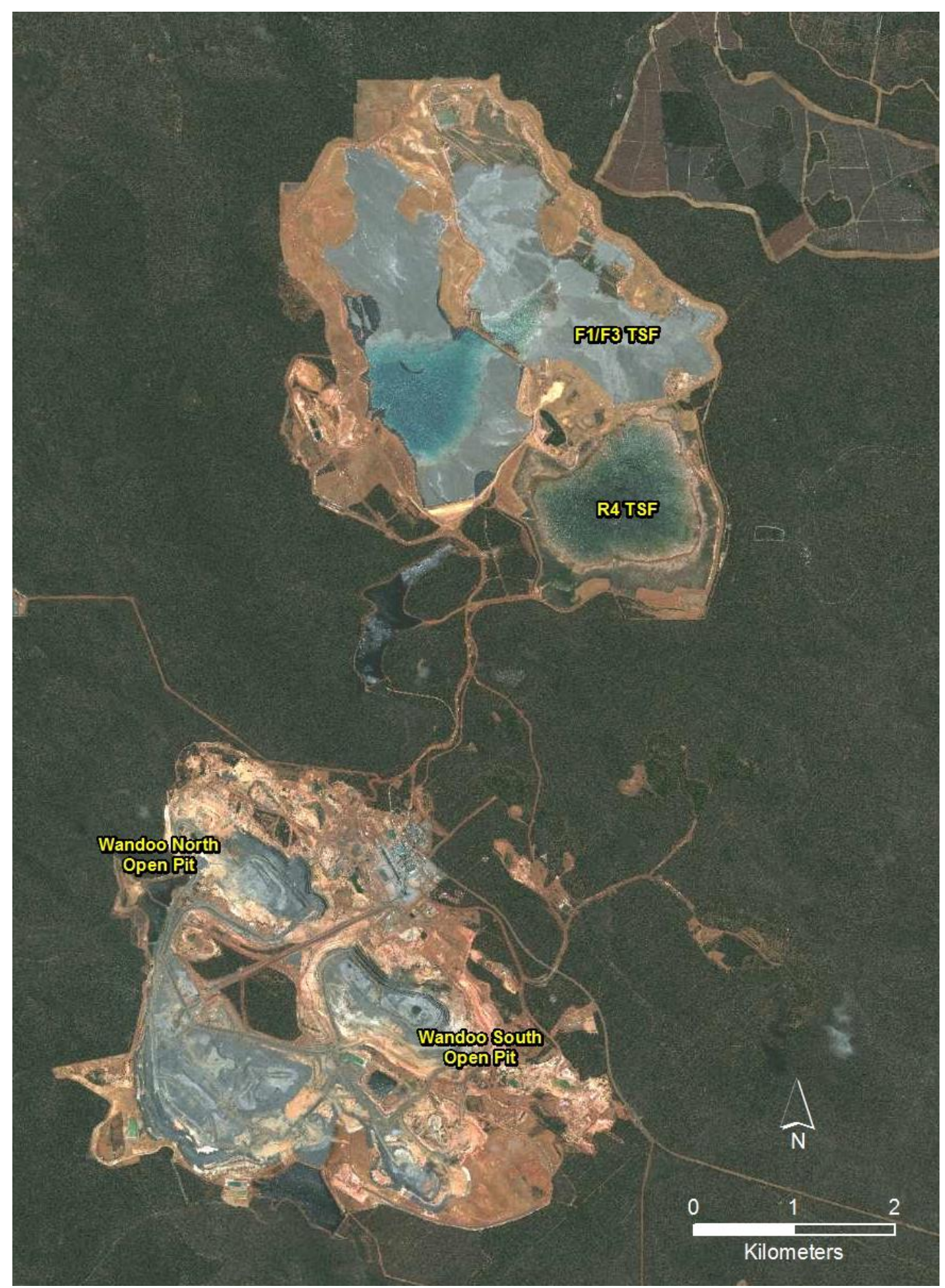

Figure 2 Key features of Newmont Boddington Gold mine site

\subsection{Mine closure studies and investigations for long term closure planning}

Over the past two years, a number of discipline experts (specialist consultants) have been commissioned to conduct specialised scientific studies and investigations to address identified knowledge gaps. Some of the gaps identified during the gap analysis require immediate attention to be included in the current revision of the closure plan whilst others address ongoing management and long term strategic planning. The key areas identified in the gap analysis process for which studies are currently being undertaken are: 
- Geochemistry and materials management.

- Landform and cover design.

- TSF rehabilitation trials and development of a Conceptual Decommissioning Plan.

- Rehabilitation materials characterisation and inventory.

- Pit lake and post-closure water balance modelling.

- Completion criteria.

A summary of the outcomes of the studies undertaken to address these focus areas is included in Section 4.

The site-based multi-functional closure team regularly interacts with the discipline experts to ensure the best solutions for long term management of NBG are identified in studies and investigations. Regular team meetings are held to discuss progress on each project. These meetings are chaired by the Newmont Senior Closure Planner responsible for the NBG site and are attended by representatives from the relevant site operational areas such as Mining/Mine Planning and Environment Departments. Addressing knowledge gaps with a group of professionals with overlapping areas of expertise has resulted in potential problems and alternative solutions being raised early in the planning process. This allows for more practical and effective solutions to be developed in a timely manner for development of the closure plan.

\subsection{Benchmarking of closure works from other mine sites}

One of the unique aspects of Newmont's closure planning process is regular benchmarking of closure activities at other mine sites across Australia. A program has been developed for undertaking benchmarking trips to regions or mine sites with features similar to Newmont mines in the Asia Pacific region. These benchmarking trips have been found to be very valuable for sharing knowledge and learning from the successes and failures of others. Recent bench marking trips have visited mines in Queensland, New South Wales and the Goldfields of Western Australia. In April 2012, a comprehensive benchmarking trip was conducted in the southwest of Western Australia visiting mineral sands, bauxite and coal mines at various stages of operation and closure. Many of these sites provide useful analogues for closure of NBG with respect to landform design, rehabilitation techniques and expected performance, formation of pit lakes, outcomes of post closure activities and land use, stakeholder consultation and completion criteria.

\subsection{Stakeholder consultation planning}

Stakeholder consultation regarding closure planning for NBG utilises the already established government liaison group and is tied in with community consultation on expansion of the project. The Boddington Gold Mine Environmental Management Liaison Group (BGMEMLG) was formed in 2001 and has become the main forum for liaising with the government to discuss issues that affect the NBG operations as a whole. A notable experience during community consultation has been the lack of interest in closure planning when discussing expansion programs to increase the mine life to over 40 years.

\subsection{Cost estimating and financial provisioning for closure liability}

Closure cost estimating and financial provisioning for NBG closure liability are undertaken in accordance with Newmont's strict guidelines to meet various regulatory requirements. The three main estimates for cost provisions are (i) Financial Assurance (closure bond) estimates; (ii) Life of Mine estimates; and (iii) Asset Retirement Obligation (ARO) estimates. These are comprehensively reviewed annually and reported through to the head office as part of the company's annual financial reporting system.

The ARO estimates involve a comprehensive and detailed analysis of all legal requirements for closure as defined by the United States Financial Accounting Standards Board (FASB) Statement 143 and includes legal/regulatory commitments, landowner agreements, contracts, verbal or written agreements made by the company as well as all other enforceable liabilities that exist in that particular financial year. The LOM 
estimates however, covers all costs to be incurred in performing closure activities associated with NBG's current LOM plan and includes all closure costs and liabilities associated with planned development of the mine irrespective of when they will be performed. The LOM costs are prepared and reviewed on a cash flow basis annually and incorporated in the long term NBG site cost model. Both estimates cover closure execution and management as well as post closure maintenance and monitoring.

As part of the review of the NBG closure plan, a comprehensive review of both LOM and FASB cost estimates is currently underway which involves a detailed evaluation of closure activities and method statements for all activities, and potential equipment and their utilisation factors and costs to develop realistic unit rates that reflect current conditions. Conceptual engineering designs, including their current revisions, provide adequate details for these unit rate estimates. In Newmont, the assumptions and criteria document is the main document that outlines in a step by step manner the basis for the estimate for each closure activity. Specialist cost estimating consultants were engaged to develop both owner operated unit rates and third party unit rates as well as realistic lump sum costs for items such as facilities demolition, specialised hazardous waste removal, etc. It is expected that results from numerous ongoing studies and performance data obtained throughout the operations phase will be used to continuously refine the cost estimates and also develop detailed designs prior to closure execution stage.

\section{$4 \quad$ Closure studies and investigations}

\subsection{Geochemistry and materials management}

\subsubsection{Geochemical characterisation of NBG waste rock}

Geochemical characterisation of NBG waste rock commenced at the early stages of the project to ensure appropriate management of the significant volume of material generated. Detailed geochemical characterisation of the various lithologies encountered during mining was conducted early in the feasibility stages and comprehensive static geochemical data was collected using drill core samples. The low buffering capacity of the NBG lithologies, due to low levels of reactive carbonates, was highlighted by a program of kinetic tests conducted in late 2000. One of the key findings from early investigations of the acid forming characteristics of NBG waste rock was the inability of standard acid base accounting (ABA) to validly account for circum-neutral buffering from primary silicates. Based on the static testing results, the majority of samples were classified as UC (uncertain) in terms of acid formation potential.

The results from this stage of geochemical testing led to a mine waste management plan based on a conservative approach of classification whereby almost all of the waste bedrock (below the regolith profile) at NBG was classified as Potentially Acid Forming (PAF) and segregated during operation. This equates to approximately $65 \%$ of the total mine waste volume being classified and managed as PAF, although the majority of the waste bedrock is characterised by Total-Sulphur (Total-S) values less than $0.3 \%$. One unique aspect in assessing Non Acid Forming (NAF)/PAF classification at NBG is that waste rock types locally contain pyrrhotite and pyrite as trace components (e.g. Total-S values less than $0.5 \%$ ), and the groundmass is typically deficient in carbonate minerals (e.g. $\mathrm{CO}_{3}-\mathrm{C}$ values less than $0.1 \%$ ).

The need for further investigation to provide a definitive geochemical classification of the NBG waste rock was highlighted by Amoah et al. (2010). A specialist consultant was therefore commissioned in 2010, to conduct investigations into the geochemical characteristics of the waste rock at NBG to increase understanding of its geochemical behaviour. The current investigation aims at providing a sound geochemical basis upon which to propose a Total-S cut-off value for differentiating between reactive and benign varieties of the andesite/diorite waste rocks at NBG. If it can be confirmed that circum-neutral hydroloysis of the silicates produces sufficient alkalinity to buffer the acidity, then a classification based on a Total-S cut-off point will provide a valid scientific basis for NAF/PAF differentiation.

Very promising results have been obtained over the past 20 months since kinetic test work commenced. The results to date indicate that the groundmass of these lithotypes contains a 'pool' of alkalinity forms 
sufficient for the circum-neutral oxidation for waste rock for at least $0.1-0.2 \%$ Total-S. Hence a sulphur cutoff value will provide a reliable basis for differentiating NAF from PAF material (Campbell et al., 2012).

\subsubsection{Development of waste rock management plan}

Specialist consultants have been engaged to develop a waste rock management plan using the results from the geochemical testing described above. The strategy is to manage the potential impacts of both waste rock and stockpiled medium grade ore in both the short and long term to prevent the requirement for long term treatment of acid and/or metalliferous drainage (AMD) post-closure. The waste rock management strategy comprises two documents, a waste rock handling manual for implementation on site and a technical supporting document which summarises all of the relevant investigations used to generate the manual.

Clear and reliable guidelines for distinguishing between NAF and PAF rock are fundamental to the development of a waste rock management strategy for NBG which can be practically implemented without significantly impacting on production. As the major lithological units of the deposit are virtually devoid of carbonate and contain only trace sulphides ( $80 \%$ of waste rock mined to date has a Total-S concentration of $<0.3 \%$ ), separating the relatively smaller quantities of PAF material from NAF will lead to substantial cost savings and long term environmental protection.

It is expected that large scale field weathering trials will be undertaken, which in combination with additional/ongoing laboratory kinetic sampling, trials of waste rock landform slope and cover designs and further investigations into hydrologeological conditions, will support ongoing refinement of the waste rock management strategy as necessary.

\subsection{Waste rock landform and cover design}

\subsubsection{Waste rock landform storage analyses}

The low grade of the NBG ore body results in the generation of large quantities of waste rock. However, regulatory commitments impose height restrictions on the waste rock landforms which coupled with the limited space has resulted in the storage of waste rock becoming a major operational and closure issue. Closely related to this is the conservative classification of NAF/PAF waste rock due uncertainties in its geochemical characteristics which has reduced the flexibility in the choice of locations to store waste rock. These issues create a further problem in the cost effectiveness of cover types to be used at closure.

The waste rock landform and cover design process is therefore intricately linked with the mine planning process throughout the operational life and especially during periods of expansion. The need to address this issue was recognised immediately after the 2008 review of the closure plan based on the updated LOM plan. A specialist mine planning consultant was employed in 2010 to conduct comprehensive analyses of the options available for optimising waste rock landform storage and to determine the associated risks with the preferred options. Working closely with the operations mine planning team, revisions of the mine plan were assessed for waste rock management aspects including scheduling, materials management, rehabilitation and surface water management, the results of which will be integrated into the mine plan.

Several iterations were made for over 20 configurations for the waste rock landforms to meet physical constraints including (i) visual impact with respect to maximum height of the landform in comparison to surrounding topography; (ii) minimisation of clearing of jarrah forest; (iii) existing tenure; (iv) construction cost; (v) location of bauxite (to be mined prior to NBG using of the area); (vi) drainage at the catchment level; and (vii) infrastructure such a power lines and a future conveyor corridor. Other constraints relating to ecological factors such as the location of (i) black cockatoo habitat; (ii) a potentially significant woylie population; and (iii) locally restricted vegetation communities such as swamps were also examined. Figure 3 shows examples of the analyses of the various options and constraints. 

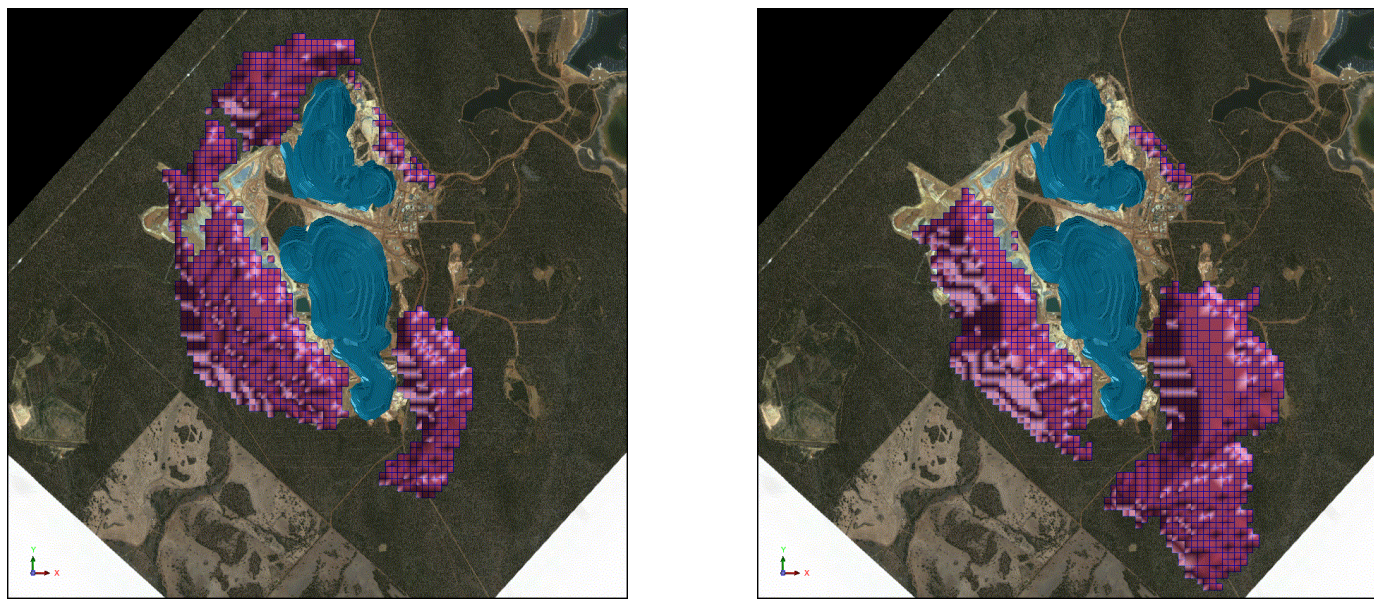

Figure 3 Analysis of waste rock landform design

The above factors posed significant challenges to the planning process for the waste rock landforms as they interact to result in conflicting outcomes. For example, constructing a landform with an increased maximum height would result in a smaller footprint and less clearing of jarrah forest for the volume of waste rock being stored. However, this also results in unacceptable visual impact and a higher long term closure risk due to the long slopes to be stabilised during rehabilitation. Similarly, decreasing the overall slope angle for the landform reduced the closure risk associated with erosion but also increased the footprint and the requirement for clearing of jarrah forest or disturbing other ecologically significant land.

After several iterations, preferred landform locations, heights and sizes were selected and integrated with the operations mine planning program. The waste rock materials dumping schedule was re-assessed to ensure that materials that require immediate encapsulation are segregated and that potential rehabilitation material such as oxide can be stored in locations where they can be accessed when required at later stages of the mine life to minimise the area required for stockpiling of materials.

\subsubsection{Landform surface water management}

Due to the large area of the waste rock landforms, surface water management becomes a critical component of long term stability. Drainage of the top surface and slopes of the waste rock landform are designed to minimise infiltration while at the same time controlling water release for long term erosional stability. Model simulations were conducted to determine the lower and upper boundaries of erosion depths using assumed parameters considered to be realistic for the site conditions and for different slopes and profiles. The surface water management design was further refined by concentrating surface water flow in sections of the landform with reduced slope length and thereby taking advantage of variations in the surrounding topography to minimise the potential for erosion of drainage structures.

\subsubsection{Landform cover analyses}

The cover design for the waste rock landform was selected based on among other things the need to (i) minimise infiltration; (ii) provide adequate cover to meet predicted erosion and vegetation performance; (iii) availability and characteristics of rehabilitation materials; and (iv) constructability on a large scale. Experience was drawn from the performance of existing rehabilitation works completed on shallow oxide pits. Several cover types and systems have been assessed in relation to regulatory commitments and Newmont standards. However, as hard rock mining and construction and rehabilitation of a waste rock landform has not been previously undertaken at NBG a comprehensive rehabilitation trial of the various options will be completed in the future to refine the current cover design and determine the most appropriate cover system. 


\subsection{TSF rehabilitation trials and conceptual decommissioning plan}

Closure and rehabilitation of TSFs to meet sustainable environmental requirements is usually one of the biggest challenges faced on mine sites. The tailings materials at NBG are relatively benign in terms of acid forming potential. However, the size of these facilities (currently over 1,500 Ha and with potential to double in size) makes it very challenging to achieve rehabilitation outcomes with acceptable ecological standards.

To facilitate strategic closure planning for the TSFs at NBG, a specialist consultant was engaged to re-assess an established rehabilitation trial and incorporate the findings into a Conceptual TSF Decommissioning Plan. The field trial was initially established in 1999 on a TSF constructed from tailings of oxide ore to develop an understanding of the effects on rehabilitation performance of topsoil, gypsum and compost application rates over various depths of gravel cover. Several investigations into the characteristics of the various cover treatments and underlying tailings material, soil water interactions and vegetation parameters were undertaken in the first three years following trial establishment.

Re-assessment of the trial in 2011 found that there had been a substantial reduction in the salinity of the tailings material and no upward movement of salt into the cover materials. The $\mathrm{pH}$ of the tailings material decreased from being extremely alkaline to neutral and high levels of exchangeable sodium in the upper layers declined substantially. Vegetation growth is vigorous and roots are prolific within the tailings profile. Little difference was observed in vegetation characteristics or physical and chemical characteristics of the soil cover and residue materials within the different cover treatments. The success of the rehabilitation trial was considerably better than anticipated at the time of trial inception and has encouraging implications for rehabilitation success of future tailings materials at NBG.

The physical and chemical characteristics of the tailings produced from mining of basement rock indicate that they are benign, but different to the oxide tailings on which the rehabilitation trial was conducted. A second trial will be constructed at NBG to evaluate the capacity of basement tailings to support vegetation and the effect of decreasing the thickness of gravel subsoil on vegetation establishment and productivity.

A Conceptual Decommissioning Plan has been developed for the TSFs based on a staged program developed for the site and discussed by Lacy and Barnes (2006). The components of the conceptual decommissioning plan include the following:

- A literature review to establish a knowledge base.

- Risk assessment and identification of knowledge gaps.

- Investigative tasks required to fill knowledge gaps.

- Closure options that achieve agreed objectives.

The Conceptual Decommissioning Plan incorporates the outcomes of a decision-making workshop that was undertaken to review and compare surface water management systems for the TSFs based on a range of project specific criteria in the categories of governance, environment, economics and social.

\subsection{Rehabilitation materials characterisation and inventory}

A specialist consultant was commissioned to develop a site wide inventory of soil and waste materials and to determine the properties of these materials with respect to their value in rehabilitation.

The materials inventory study identified that there is currently a deficit of subsoil gravels and topsoil materials on site for rehabilitation of landforms associated with the life of mine plan, which includes allowances for rehabilitating areas that have not yet been disturbed. The deficit can be addressed through stripping of adequate materials during future expansion of the waste rock landforms and TSFs. Enough oxide material is available for rehabilitation; however, most of this is in situ and will need to be segregated for rehabilitation rather than being placed within waste rock landforms as general waste. 
Critical functions of the TSF and waste rock landform cover systems include their capacity to maintain the integrity of the landforms and to support vegetation. Each of these functions was considered for the materials available for construction of the covers based on their physical and chemical properties.

The physical integrity of the landforms will depend on the resistance of the constructed covers to erosion. The topsoil and subsoil gravel materials at NBG are likely to be relatively resistant to erosion because their high gravel content. Additionally, the fine fractions of the topsoil and gravels have a relatively high hydraulic conductivity allowing rainfall to infiltrate rapidly.

The properties of the oxide materials at NBG are likely to be the most important factor when considering erosion risk due to their very low saturated hydraulic conductivity. It is likely that the oxide materials will not allow infiltration at a sufficient rate to prevent saturation of the overlying gravel subsoil and topsoil during high rainfall rain events. Once saturation of these upper layers occurs, surface runoff could be expected creating the risk of rilling and gullying (Jasper and Braimbridge, 2006).

The oxide materials sampled were on average sodic, slightly saline and ranged from slightly to nondispersive. The level of salinity may reduce with leaching over time, and this may in turn allow increased dispersion, leading in turn to greater risk of tunnelling and erosion. As a counter to this, root development through the oxide profile will contribute to enhanced stability.

An important objective of the cover systems is to minimise net infiltration into the underlying material. There was a wide range of water retention characteristics measured for the various soil materials assessed, with the amount of gravel present being the most influential factor affecting the ability of the soil materials to store and release water. As expected, the oxide materials had the highest water holding capacity.

The capacity of constructed covers to support plant growth depends primarily on the availability of water and nutrients. With the oxide materials a large proportion of annual average rainfall could be stored as plant-available water (PAW) as they have a PAW capacity ranging from approximately $60-230 \mathrm{~mm} / \mathrm{m}$ depth. However, the very low hydraulic conductivity of the oxide materials could constrain the storage potential of these materials. The topsoil and subsoil gravels have less water storage capacity, due in large part to their very high gravel content.

Access to stored water in soils also depends on root exploration through the materials. More than half of the oxide samples measured had the potential to hard-set to an extent that may restrict root growth of some plants (Cochrane and Aylmore, 1997). However, observation of constructed soils in rehabilitation areas at NBG reveals root exploration to at least three metres with no obvious physical restrictions.

In terms of chemical fertility, nutrient levels in constructed soil covers will be broadly equivalent to those in natural soils in the region of the mine.

\subsection{Pit lake and post-closure water balance model}

Upon cessation of dewatering of the mining area, pit lakes will develop in the open pit voids through inflow of groundwater, surface water runoff from the surrounding catchment (including from waste rock landforms and TSFs) and diversion of the Thirty-Four Mile Brook. A site wide closure water balance and hydrochemical model was developed in 2011, to be used as a predictive tool to support the ongoing development of the closure plan and the design of the mine facilities. The GoldSim model developed is flexible enough to incorporate ongoing design changes and improvements in understanding of hydrological and hydrochemical parameters during operations.

The GoldSim model was used as the basis for a hydrochemical model to provide preliminary estimates of water quality at specific locations at discrete time periods post closure. The water quality at each location was predicted by mixing waters from different sources, evapoconcentrating the mixture (as appropriate) and then allowing the resulting water to equilibrate with specified mineral and atmospheric gas species. The indicative estimates of hydrochemistry suggest that the proposed management regime is appropriate for the site conditions. It is expected that ongoing geochemical characterisation studies will help improve the ability to predict the evolution of site-wide water chemistry. 
Base case predictions from the water balance model were generated using daily data measured from 1960 to 2010, the drier portion of the long term record at this weather station. Sensitivity analyses were undertaken to (i) ascertain model sensitivity to input parameters; and (ii) identify and prioritise parameters for which more monitoring data must be gathered during the operational period for refinement of the model. Model runs were used to evaluate rehabilitation effectiveness, optimum AMD treatment rate, pit discharge potential, pit lake evaporation estimates and alternative climate scenarios (Table 1).

\section{Table 1 Sensitivity analyses for post-closure water balance model}

\begin{tabular}{|c|c|}
\hline Parameter & Scenarios Simulated \\
\hline \multirow[t]{3}{*}{ Rehabilitation effectiveness } & $\begin{array}{l}\text { Rehabilitation very successful - increased evapotranspiration from } \\
\text { TSFs. }\end{array}$ \\
\hline & $\begin{array}{l}\text { Revegetation and erosion control poor - increased waste rock } \\
\text { landform infiltration rate. }\end{array}$ \\
\hline & $\begin{array}{l}\text { Revegetation and erosion control poor - reduced waste rock landform } \\
\text { runoff. }\end{array}$ \\
\hline Optimum AMD treatment rate & $\begin{array}{l}\text { Maximum treatment rate varied from } 14 \text { litres per second }(\mathrm{L} / \mathrm{s}) \text { to } \\
100 \mathrm{~L} / \mathrm{s} \text {. }\end{array}$ \\
\hline Pit discharge potential & Precipitation reduced to $50 \%$ of long term average. \\
\hline \multirow{2}{*}{$\begin{array}{l}\text { Uncertainty in pit lake } \\
\text { evaporation estimates }\end{array}$} & Pond evaporation rate reduced to $60 \%$ of pan evaporation. \\
\hline & Pond evaporation rate increased to $90 \%$ of pan evaporation. \\
\hline \multirow[t]{4}{*}{ Alternative climate scenarios } & $\begin{array}{l}\text { Climate change - based on climate model predictions which indicate a } \\
\text { maximum reduction of } 20 \% \text { in annual precipitation and a maximum } \\
\text { increase of } 7 \% \text { in evaporation by } 2070 \text {. }\end{array}$ \\
\hline & Very dry - precipitation reduced to $80 \%$ of long term average. \\
\hline & Wet - based on wetter part of the historical record. \\
\hline & Very wet - precipitation increased by $20 \%$ of long term average. \\
\hline
\end{tabular}

The sensitivity analyses indicate that the pit lakes will discharge to the downstream section of Thirty-Four Mile Brook under all realistic conditions with filling times ranging from 40-110 years. The performance of the pit lakes is relatively insensitive to the evaporation rate as a result of the large catchment area reporting to the lake and the relatively wet winter conditions compared to pit lakes in most other areas of Australia. Figure 4 shows the results of model runs for the climate scenarios considered.

During the early filling period the pit lake water quality will be mostly influenced by groundwater inflow water quality, resulting in total dissolved solids (TDS) concentrations around 1,600 $\mathrm{mg} / \mathrm{L}$. When the pit lake chemistry stabilises, the TDS concentration is predicted to be moderately high $(1,200 \mathrm{mg} / \mathrm{L})$, consisting mostly of sodium and chloride, with trace metals/metalloids at or below analytical detection.

The GoldSim model will be updated to reflect changes in mine plan and landform design and investigate potential water treatment demands. The indicative chemistries predicted at key discharge locations will be compared with downstream environmental values and relevant guidelines to determine whether further management or treatment of outflows may be required. 


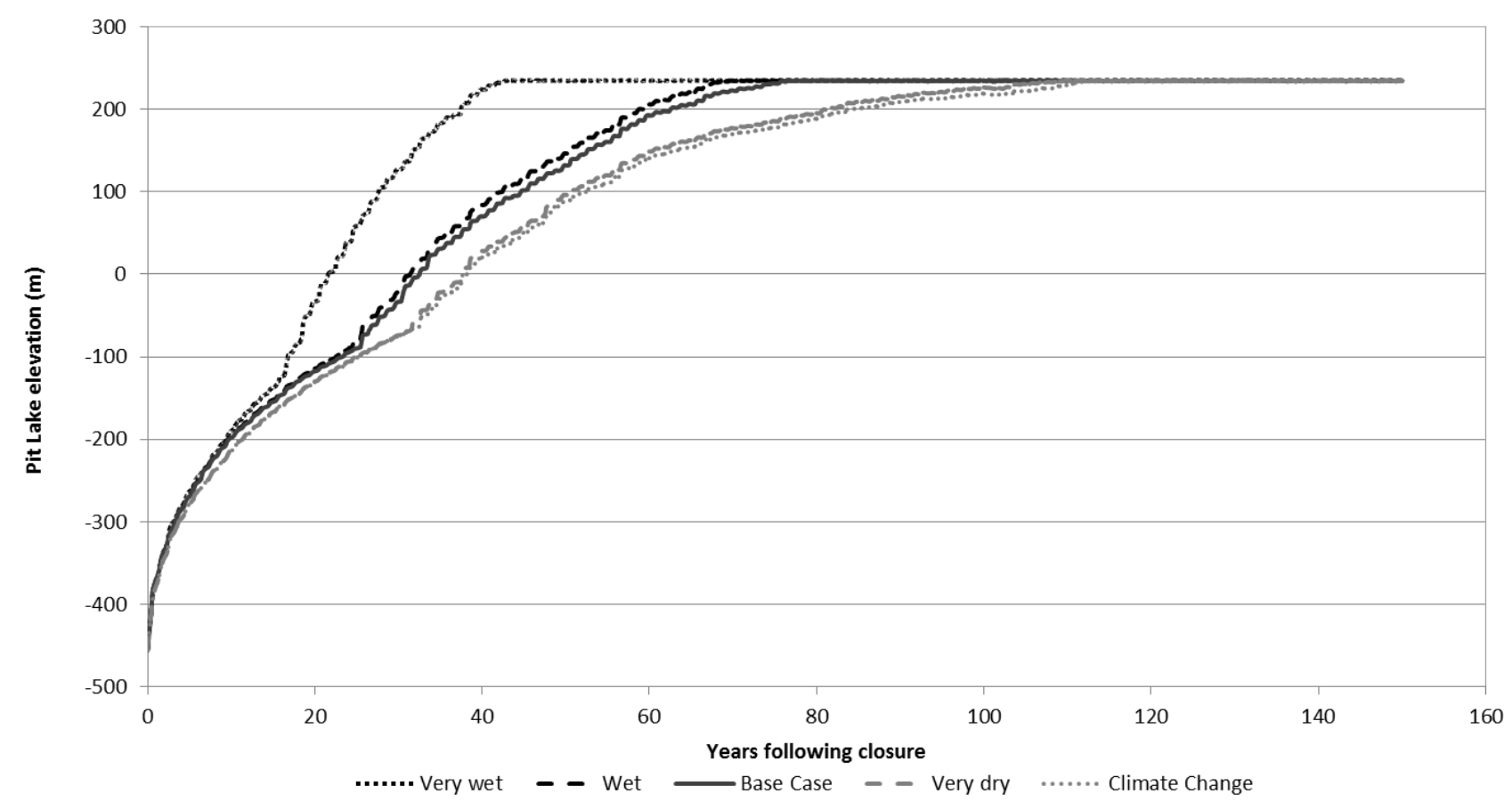

\section{Figure 4 Pit lake filling curves}

\subsection{Development of completion criteria}

Mine closure completion criteria are perhaps the most important aspect of a closure planning document as they provide the basis upon which successful rehabilitation and mine closure are determined. Bentel (2009) outlines some of the benefits of developing appropriate completion criteria including (i) providing a basis for designs and method statements; (ii) describing metrics against which commitments, obligations and stated closure objectives can be measured; and (iii) forming the basis for developing post closure monitoring and maintenance plans. Virtually all regulatory authorities and even some community interest groups as well as company internal guidelines rely on completion criteria in assessing progress of closure for potential future relinquishment or adjustments in the magnitude of closure bonds. The Environmental Protection Authority (2006) requires that, mine closure completion criteria should:

- Allow success to be measured within realistic timeframes.

- Are sufficiently precise to allow outcomes to be effectively audited, but are also flexible when required.

- Are based on sound scientific principles.

- Acknowledge the consequences of permanent changes to landforms, soils and hydrology.

A comprehensive literature review was completed to identify closure related requirements and commitments contained within government regulations, approvals documents and company policies and standards. Completion criteria for shallow oxide open pits mined historically in the area had previously been developed but not formally endorsed by relevant stakeholders. These were considered during development of completion criteria for the whole site, along with the criteria used at other mine sites in the southwest region of Western Australia.

A framework of broad objectives was developed, based on potential final land uses for the area and expected closure performance. The closure objectives are supported by more specific completion criteria, with each criterion supported by an appropriate measurement approach. The objectives cover aspects ranging from physical elements (e.g. stability, drainage, erosion and suitability of material to support plant growth) through to biological aspects (e.g. vegetation, ecosystem processes and fauna habitat) and post- 
closure management. The completion criteria are general enough to be applicable to the entire site while being specific enough to require high quality outcomes.

As the physical elements of rehabilitation are planned and constructed before biological components can be established, the framework of completion criteria is applied to three sequential phases:

1. Planning and landform construction.

2. Surface preparation and vegetation establishment.

3. Monitoring, remediation and relinquishment.

The success of revegetation on mine sites is typically compared to natural (un-mined) analogues. The NBG closure criteria framework has been developed in this way, particularly for vegetation parameters. As more information becomes available from ongoing and future investigations and trials the completion criteria will continue to be reviewed and refined based on the best available data at the time.

\section{$5 \quad$ Conclusions}

Closure planning for a large mine site in a sensitive environment like NBG is a complex process. The planning process must start at the very early stages and must be consistently managed throughout the various phases of the mine operation until closure. A large number of investigations, studies and field trails should be conducted and monitored over a long period to gather the information required to support the development of a useful and relevant closure plan.

Improved outcomes can be achieved for closure plans by the integration of mine planning and closure planning. However, this process is not always easy due to the different focus of the personnel who work in these areas. As experienced at NBG, significant benefits can be gained by working with a multi-functional team derived from all relevant areas of mine operation and including external technical experts to achieve the best closure planning outcome.

\section{Acknowledgement}

The authors wish to acknowledge the work undertaken by DumpSolver, Graeme Campbell \& Associates, Outback Ecology, Schlumberger Water Services and SLR Consulting which forms the basis for this paper.

\section{References}

Amoah, N., Haymont, R. and Campbell, G. (2010) Benefits of Timely and Valid Geochemical Characterisation of Mine Waste for Life of Mine and Closure Planning, A Case Study of Newmont Boddington Gold Mine in Western Australia, in Proceedings of the 14th International Conference on Tailings and Mine Waste, Tailings and Mine Waste 2010, Vail, Colorado, USA, 17-20 October 2010, pp. 253-262.

Bentel, G.M. (2009) Key Closure Planning Considerations, in Proceedings Fourth International Conference on Mine Closure (Mine Closure 2009), A.B. Fourie and M. Tibbett (eds), 9-11 September 2009, Perth, Australia, Australian Centre for Geomechanics, Perth, pp. 41-54.

Campbell, G., Haymont, R. and Amoah, N. (2012) A Testing Approach to Assess the Weathering Behaviour of Lithotypes Characterised by a Trace-sulphide/Carbonate-deficient Mineralogy: Application to Altered Andesites/Diorites at the Boddington Gold Mine, Western Australia, in Proceedings 9th International Conference on Acid Rock Drainage, W.A. Price, C. Hogan, G. Tremblay (eds), 20-26 May 2012, Ottawa, Canada (in print).

Cochrane, H.R. and Aylmore, L.A.G. (1997) Assessing Management-Induced Changes in the Structural Stability of Hardsetting Soils, Soil and Tillage Research, Elsevier, Vol. 20, pp. 123-132.

DMP and EPA (2011) Department of Mines and Petroleum; Environmental Protection Authority. Guidelines for Preparing Mine Closure Plans, Perth, Western Australia, June, $78 \mathrm{p}$.

Environmental Protection Authority (2006) Guidance for the Assessment of Environmental Factors (in accordance with the Environmental Protection Act 1986), Rehabilitation of Terrestrial Ecosystems No. 6, Perth, Western Australia, $37 \mathrm{p}$.

Jasper, D.A. and Braimbridge, M.F. (2006) Waste Characterisation for Optimal Landforms, in Proceedings GEMG Conference, 24-26 May 2006, Kalgoorlie, Australia, Goldfields Environmental Management Group, Kalgoorlie, pp. 128-145.

Lacy, H. and Barnes, K. (2006) Tailings Storage Facilities; Decommissioning Planning is Vital for Successful Closure, in Proceedings First International Seminar on Mine Closure (Mine Closure 2006), A.B. Fourie and M. Tibbett (eds), 13-15 September 2006, Perth, Australia, Australian Centre for Geomechanics, Perth, pp. 139-148. 